\title{
Long Bone Non-Unions and Malunions: Risk Factors and Treatment Outcomes in Calabar, Southern Nigeria
}

\author{
Ikpeme A. Ikpeme $^{1 *}$, Nkese E. Mkpanam², Innocent E. Abang ${ }^{1}$, Ngim E. Ngim ${ }^{1}$, Anthony M. Udosen ${ }^{1}$ \\ ${ }^{1}$ Department of Orthopaedics \& Traumatology, University of Calabar, Calabar, Nigeria; ${ }^{2}$ Department of Community Medicine, Uni- \\ versity of Calabar, Calabar, Nigeria. \\ Email: *iaikpeme@yahoo.com
}

Received August $28^{\text {th }}, 2013$; revised September $25^{\text {th }}, 2013$; accepted October $1^{\text {st }}, 2013$

Copyright (C) 2013 Ikpeme A. Ikpeme et al. This is an open access article distributed under the Creative Commons Attribution License, which permits unrestricted use, distribution, and reproduction in any medium, provided the original work is properly cited.

\begin{abstract}
Background: Diaphyseal non-unions and malunions constitute significant morbidities in fracture care. Fracture treatment modalities seek to restore anatomic orientation and functional rehabilitation as soon as possible after a fracture incident. Malunions and non unions present a treatment challenge with the need for prolonged hospitalization, multiple surgical interventions and economic burden. In the developing world, traditional bonesetting practices are popular and these often result in a host of preventable complications. The added socioeconomic costs of treating these complications present a considerable strain on the resources of these already fragile economies and households. Aim: To document the risk factors, treatment options and outcomes for diaphyseal non-unions and malunions in our environment. Patients and Methods: Fifty-two consecutive patients comprising 37 non-unions and 15 malunions who presented in the orthopaedic unit of a tertiary hospital in Southern Nigeria were evaluated. Information sought included biodata, location of pathology, type of incident fracture, local risk factors including traditional bonesetting; treatment options and final outcomes. Information obtained was analyzed using SPSS version 20 (IBM, New York). Results are presented in simple frequency tables. Results: There were 34 males and 18 females $(\mathrm{M}: \mathrm{F}=1.9: 1)$ with a mean age of $38.76 \pm 14.55$ years. There were 37 non-unions and 15 malunions. The femur was the commonest site of pathology in $21(40.4 \%)$ cases, and among the non-unions, the atrophic variety was the commonest type $(\mathrm{n}=26 ; 70.3 \%)$. The mean fracture-to-surgery interval was $11.35 \pm 7.95$ months and traditional bonesetting was the commonest risk factor $(n=36 ; 69.2 \%)$. Plate and screw Osteosynthesis with bonegraft augmentation was the commonest treatment modality and the overall union rate was $94 \%$. Conclusion: Traditional bonesetting plays a major role in the health seeking behaviour of many African societies. The complications are varied and add to the overall socioeconomic burden of fracture care in these developing economies. Identification of traditional bonesetting practices as an important risk factor should translate into a focus on these practices in preventive public health decisions in fracture care. Continuing public health education backed by political will and can potentially drive a paradigm shift in health seeking attitudes in the developing world.
\end{abstract}

Keywords: Non-Union; Malunions; Traditional Bonesetting; Resource-Poor Economy

\section{Introduction}

Long bones serve to support the trunk providing a stable framework for propulsion and facilitate pre-hension, reach and grasp, functions which are important in the homo erectus. Non-unions are estimated to occur in $1 \%$ $10 \%$ of humeral shaft fractures treated non-operatively, $10 \%-15 \%$ of humeral fractures treated operatively, $0.9 \%$ of femoral shaft fractures treated with modern intramedullary nailing techniques and $2 \%$ to $10 \%$ of all tibial fractures in the United States [1-3], and result in a large number of therapeutic interventions with significant so-

\footnotetext{
${ }^{*}$ Corresponding author.
}

cio-economic costs [1-4]. The factors that cause non unions may be considered as those inherent in the fracture, patient (host) factors and surgical (treatment) factors. They include the involved bone and bony region injured, the degree of soft tissue injury, patient's age, the presence of co-morbidities, smoking and non-steroidal anti-inflammatory drug (NSAID) abuse. Unstable fixation, excessive iatrogenic stripping of the periosteum, infection, malnutrition, chronic alcoholism and injudicious interventions by traditional bonesetters are other risk factors for nonunions $[1,5,6-8]$.

The definition of non-union has undergone an evolution. Prior to 1998 , the definition of the condition was time- 
bound as failure of union in a fracture $\geq 9$ months post injury with no observable progressive signs of healing for at least 3 months [9]. The prevention of prolonged morbidity and recognition of the need for early intervention necessitated a review of the definition to be the absence of progressive signs of bone healing on radiographs over 3 consecutive months $[4,9,10]$. Some regions still however define non-union as a failure to heal within the time boundaries of injury and treatment $[6,7]$. The tibia is the most commonly affected bone $[1,4,10]$, owing to its subcutaneous location and relative lack of muscle cover except in the postero-lateral aspect.

Non-unions are classified in different ways, each with a therapeutic and prognostic significance. Atrophic nonunions have traditionally been ascribed to failure of healing biology, while hypertrophic non-unions are said to occur in the presence of excessive movement or infection in a setting of appropriate healing biological factors. Therapeutically therefore, while bonegrafts are always necessary in atrophic non-unions, stabilization with compression and reduction of excessive movements may be all that is required in hypertrophic non-unions. In terms of their anatomic location, Non-unions may be diaphyseal or metaphyseal. Diaphyseal non-unions have a reduced biologic potential compared to metaphyseal non-unions, but are amenable to a wider range of treatment/stabilization options [1]. Non-unions may also be classified as aseptic or infected. While the goal of management of aseptic non-union is the promotion of stability and union, the goal of treatment of an infected non-union is to first convert it into a non-infected non-union and then treat the fracture.

Acceptable reduction in the tibia is characterized as greater than $50 \%$ cortical contact, less than $10^{\circ}$ angulation in any plane, less than $5^{0}$ valgus or varus tilt, less than $10^{\circ}$ of anterior or posterior angulation, less than $10^{\circ}$ of rotation and less than $10 \mathrm{~mm}$ leg length discrepancy. Fracture site distraction is not tolerated because a $5 \mathrm{~mm}$ distraction may increase healing time to $8-12$ months [11]. The treatment of diaphyseal non-unions involves creating fresh bone ends and restoration of marrow continuity, stable fixation with compression of the non-union and augmentation of bone healing using biologic and nonbiologic agents like low-intensity pulsed ultrasound stimulation, electrical bone growth stimulation, bone grafts and bonegraft substitutes with osteobiological agents.

A malunion occurs when a fracture has healed in a non-anatomic or unacceptable attitude with respect to alignment, length and angulation, often with significant functional impairment especially in the lower limbs. Generally, greater than $15 \mathrm{~mm}$ shortening, $10^{\circ}$ varus or valgus angulations, $10^{\circ}$ recurvatum, $10^{\circ}$ internal rotation and $15^{0}$ external rotation are unacceptable for tibial fractures
[12]. In the upper limb, malunions often present more of a cosmetic than functional nuisance. Generally, malunions frequently result from conservative treatment of fractures, failure to adhere to physicians' instructions, ill-advised weight bearing and injudicious interventions by traditional bonesetters. The treatment of long bone malunion aims to correct translational, rotational and angular deformities and achieve a cosmetically and functionally accepted limb. This often involves osteoclasis, open reduction and internal fixation using intramedullary rods or plate and screw assemblies and various types of osteotomies. Understanding the biology of fracture healing is essential and bonegraft augmentation may be required. The aim of this study is to document the risk factors, treatment options and outcomes for long bone diaphyseal nonunion and malunions in our environment.

\section{Materials and Methods}

A study of 52 consecutive patients with 15 malunions and 37 non-unions is over a 2-year period. Patients were evaluated for age, sex, location of pathology, type of incident fracture, risk factors for malunions and non-union, type of non-union, treatment options and final outcomes. Information obtained was analysed using SPSS statistics, Version 20 (IBM Corp, New York).

\section{Results}

There were 52 cases of long bone diaphyseal malunions and non-unions in this series. There were 34 males and 18 females (M:F $=1.9: 1)$ with a mean age of $38.76 \pm$ 14.55 years. There were a total of 15 malunions and 37 non-unions. Of the non-unions, there were $26(70.3 \%)$ atrophic, 6(16.2) hypertrophic and 5 septic (13.5\%) varieties. The incident fracture was closed in 41 cases and open in 11 patients. Forty-two $(80.7 \%)$ patients had at least secondary level education while $10(19.3 \%)$ had primary level or no education. Thirty-eight (73.1\%) patients were employed in the public or private sector, $13(25 \%)$ were students and 1 patient (1.9\%) was unemployed. The mean fracture-surgery interval was $11.35 \pm 7.95$ months and the femur was the commonest site of pathology in $21(40.4 \%)$ patients followed by the tibia in $16(30.8 \%)$ patients. Union was achieved in $47(90.4 \%)$ patients after the first surgical intervention. Five patients (9.6\%) required more than one surgical intervention, and out of these, union was subsequently achieved in two. Non-union persisted in three patients. Two out of these 3 cases were infected non-unions and 1 was atrophic. The overall union rate was therefore $94 \%$ (Table 1).

In terms of risk factors, traditional bonesetting was the commonest being present in 36(69.2\%) patients followed by open fractures in $6(11.5 \%)$ patients (Table 2). Plate 
and screw osteosynthesis with bonegraft augmentation was the commonest treatment option and was used in 28(53.8\%) cases (Table 3$)$.

Table 1. Clinical parameters.

\begin{tabular}{|c|c|c|c|}
\hline \multicolumn{2}{|c|}{ Variable } & \multirow{2}{*}{$\begin{array}{c}\begin{array}{c}\text { Malunion } \\
\mathbf{n ( \% )}\end{array} \\
12(80)\end{array}$} & \multirow{2}{*}{$\begin{array}{c}\begin{array}{c}\text { Non-union } \\
\mathbf{n}(\%)\end{array} \\
22(57.5)\end{array}$} \\
\hline Gender & Male & & \\
\hline & Female & $3(20)$ & $15(40.5)$ \\
\hline & Total & $15(100)$ & $37(100)$ \\
\hline \multirow[t]{3}{*}{ Incident fracture } & Open fracture & $3(20)$ & $9(24.3)$ \\
\hline & Close fracture & $12(80)$ & $28(75.7)$ \\
\hline & Total & $15(100)$ & $37(100)$ \\
\hline \multirow[t]{5}{*}{ Education level } & Tertiary & \multicolumn{2}{|c|}{$19(36.5)$} \\
\hline & Secondary & \multicolumn{2}{|c|}{$23(44.2)$} \\
\hline & Primary & \multicolumn{2}{|c|}{$9(17.3)$} \\
\hline & No education & \multicolumn{2}{|c|}{$1(1.9)$} \\
\hline & Total & \multicolumn{2}{|c|}{$52(100)$} \\
\hline \multirow[t]{4}{*}{ Type of non-union } & Atrophic & \multicolumn{2}{|c|}{$26(70.3)$} \\
\hline & Hypertrophic & \multicolumn{2}{|c|}{$6(16.2)$} \\
\hline & Infected & \multicolumn{2}{|c|}{$5(13.5)$} \\
\hline & Total & \multicolumn{2}{|c|}{$37(100)$} \\
\hline \multirow[t]{8}{*}{ Anatomic location } & Clavicle & \multicolumn{2}{|c|}{$1(1.9)$} \\
\hline & Humerus & \multicolumn{2}{|c|}{$9(17.3)$} \\
\hline & Radius & \multicolumn{2}{|c|}{$3(5.7)$} \\
\hline & Ulna & \multicolumn{2}{|c|}{$2(3.8)$} \\
\hline & Femur & \multicolumn{2}{|c|}{$21(40.4)$} \\
\hline & Tibia & \multicolumn{2}{|c|}{$16(30.8)$} \\
\hline & Total & \multicolumn{2}{|c|}{$52(100)$} \\
\hline & Mean \pm SD & Minimum & Maximum \\
\hline Age(years) & $38.76 \pm 14.55$ & 12 & 74 \\
\hline $\begin{array}{c}\text { Duration of } \\
\text { symptoms (months) }\end{array}$ & $11.35+7.95$ & 1 & 27 \\
\hline \multirow[t]{3}{*}{ Outcomes } & $\begin{array}{l}\text { Union achieved after } \\
\text { first surgery }\end{array}$ & \multicolumn{2}{|c|}{$47(90.4)$} \\
\hline & $\begin{array}{l}\text { Union not achieved } \\
\text { after first surgery }\end{array}$ & \multicolumn{2}{|c|}{$5(9.6)$} \\
\hline & Total & \multicolumn{2}{|c|}{$52(100)$} \\
\hline
\end{tabular}

Table 2. Risk factors.

\begin{tabular}{ccc}
\hline Variable & $\begin{array}{c}\text { Malunion } \\
\mathbf{n ( \% )}\end{array}$ & $\begin{array}{c}\text { Non-union } \\
\mathbf{n ( \% )}\end{array}$ \\
\hline Traditional bonesetting & $12(80)$ & $24(64.9)$ \\
Plate and screw osteosynthesis & - & $5(13.5)$ \\
Intramedullary nail osteosynthesis & - & $1(2.7)$ \\
Local infection & $1(6.7)$ & $1(2.7)$ \\
Open fracture & $2(13.3)$ & $3(8.1)$ \\
Severely comminuted fracture & - & $1(2.7)$ \\
Wide displacement & - & $1(2.7)$ \\
Total & $\mathbf{1 5 ( 1 0 0 )}$ & $\mathbf{3 7 ( 1 0 0 )}$ \\
\hline
\end{tabular}

Table 3. Treatment options.

\begin{tabular}{ccc}
\hline Variable & $\begin{array}{c}\text { Malunion } \\
\mathbf{n ( \% )}\end{array}$ & $\begin{array}{c}\text { Non-union } \\
\mathbf{n}(\%)\end{array}$ \\
\hline $\begin{array}{c}\text { Plate and screw osteosynthesis } \\
\text { with bonegraft }\end{array}$ & $8(53.3)$ & $20(54.1)$ \\
$\begin{array}{c}\text { Plate and screw osteosynthesis } \\
\text { without bonegraft }\end{array}$ & $2(13.3)$ & $3(8.1)$ \\
IM nail osteosynthesis with \\
$\begin{array}{c}\text { bonegraft } \\
\text { IM nail osteosynthesis without } \\
\text { bonegraft }\end{array}$ & $2(13.3)$ & $5(13.5)$ \\
Linear rail with bonegraft & - & $1(2.7)$ \\
Linear rail without bonegraft & $2(13.3)$ & $3(8.1)$ \\
$\quad$ Cast bracing & 4 & $3(8.1)$ \\
Total & $1(6.7)$ & $2(5.4)$ \\
& $\mathbf{1 5 ( 1 0 0 )}$ & $\mathbf{3 7 ( 1 0 0 )}$ \\
\hline
\end{tabular}

\section{Discussion}

Fracture repair techniques continue to evolve in orthopaedics, the aim being to restore the injured bone to its preinjury functional status as soon as possible. Non-unions and malunions are severe complications of fracture repair resulting in shortening, angular deformities and rotational deformities [6]. Minimal displacement, adequate stability, sufficient nutrition and absence of infection are some of the factors that support fracture repair. Western literature identify the risk factors for non-union to include displacement, smoking/nicotine use, infection, magnitude of injury, biomechanical instability, malnutrition and vitamin deficiency, iatrogenic factors, diabetes mellitus and nonsteroidal anti-inflammatory drugs use [6,7,13-15]. The role of osteoporosis is inconclusive [13]. Diaphyseal nonunions and malunions are common problems in orthopaedics and often necessitate multiple surgical interventions and prolonged hospitalization to treat, as well as the use of non-surgical treatment adjuncts to stimulate fracture union [9]. Years of disability, the risk of amputation and the significant socioeconomic burden of these conditions make their treatment often frustrating to the surgeon and the patients. Their prevention is therefore the preferred option and is hinged on an understanding of the risk factors with respect to the patient, the fracture and the sociocultural environment $[9,13,16]$.

There were more males than females in this series, and more non-unions compared to malunions. The male preponderance and mean age of the patients $(38.76 \pm 14.55$ years) within the first four decades of life agree with data from Asian and Western studies [7,17]. Fractures are commoner in males and within the first four decades of life in our environment. Seventy-three percent of the patients were gainfully employed in the public or private sectors at the time of the antecedent injury. The socioeconomic costs of prolonged disability, prolonged hospitalization and multiple surgical interventions inherent in these con- 
ditions is well documented in different regions of the world and arise from a variety of factors [7,9]. In our setting with a fragile economy the involved age bracket is the dominant productive group and the economic costs of their injuries and consequent treatment puts direct pressure on the economic viability of their households. This is so because there is no social support and universal insurance system to help alleviate the financial burden of their treatment.

The femur was the commonest site of pathology in this series. This differs from other literature from Asia and the Western world which report the tibia and forearm with the highest rates [7,17-19]. The role of traditional bonesetting in African society is documented in other studies [20-22]. As this study shows, the incident fracture was close in $41(79 \%)$ cases. Orthodox fracture repair techniques like interlocking nails and plate \& screw osteosynthesis would have been offered to these patients with the documented advantages of stable anatomical reconstruction and early mobilization, and early return to economically productive activities. However, 36(69.2\%) patients chose to be treated by traditional bonesetters and only returned to seek orthopedic surgical care when the complications had developed at a mean fracture-surgery interval of $11.35 \pm 7.95$ months. Considering that $42(80.7 \%)$ of the patients had at least secondary level education and $38(73.1 \%)$ of them were gainfully employed, it appears that neither educational level nor socio-economic status have any inhibitory influence on the choice of traditional bonesetting as the option of first choice in patients with fractures in our environment. Lower limb complications with attendant deformity and limb-length inequality ultimately force the choice and need for orthopaedic surgical intervention.

Plate and screw osteosynthesis with bonegraft augmentation was the treatment option in the majority of our patients $(\mathrm{n}=28 ; 53.8 \%)$. This may be explained by the majority cases being atrophic non-unions. Also, in a society where orthopaedic surgical care is not the option of first choice among the majority, augmenting the chances of healing at first contact must be seen as an integral part of the first treatment plan. This philosophy seems to be consistent in the developing world [20,23]. Consistency in improved outcomes compared to the outcomes of traditional bonesetting will ultimately sway confidence from age-old suboptimal traditional bonesetting practices that have been sustained by erroneous cultural beliefs in the supernatural powers of the traditional bonesetters. Union was achieved in $47(90.4 \%)$ of the patients after the first surgical intervention. Five patients $(9.6 \%)$ required more than one operative intervention, with union subsequently achieved in two of them. Persistent non-union occurred in 3 patients after the second operative intervention. These may have benefited from such augmentations as low in- tensity pulsed ultrasound stimulation or non-invasive electrical bone growth stimulation. These options are not accessible within our healthcare system currently. Our overall union rate of $94 \%$ however compares favourably with the results of other studies from the developing world $[7,20,23]$. This study focused on risk factors within the local fracture environment. The role of systemic risk factors like smoking/nicotine use, diabetes, NSAIDS use and malnutrition is well documented and addressing these issues is an integral part of fracture treatment protocol in our institution. The role of traditional bonesetting as a risk factor for non-unions and malunions is important because it is a potential focus of public health enlightenment intervention in our locality. By the application of herbal formentations, scarifications, ill-informed splinting and excessive massage protocols, traditional bonesetting presents the risk of the creation of local ischaemia, subclinical infections and biomechanical instability in the pathogenesis of malunions and non-unions.

\section{Conclusion}

Diaphyseal non-unions and malunions are associated with significant morbidity especially in the lower limb where limb-length inequality, malrotation and malalignment can cause severe functional deficiencies. The treatment of these conditions also results in a severe economic burden for these patients with such issues as prolonged hospitalization, multiple surgical interventions and application of expensive adjunctive treatment modalities. Traditional bonesetting plays a significant role in the health care seeking behaviour of people in African societies. While cultural beliefs and financial consideration continue to fuel its popularity, the long-term complications and overall socioeconomic cost of treating these complications should drive a paradigm shift in health-seeking behaviours in the developing world. However, identifying and addressing this risk factor in the public health enlightenment intervention processes is a necessity if these complications are to be prevented in these resource-challenged economies. This study suggests that neither educational level nor gainful employment has addressed healthcare issues fueled by age-long erroneous cultural bias and beliefs. Aggressive health education campaigns, supported by political will, should help drive a paradigm shift in health seeking behaviors and interventions.

\section{REFERENCES}

[1] K. J. Pugh and S. R. Rozbruch, "Non-Unions and Malunions," In: M. R. Baumgaertner and P. Tornetta III, Eds., Orthopaedic Knowledge Update, American Academy of Orthopaedic Surgeons, 2011, pp. 115-130.

[2] J. O. Angleu, M. T. Archdeacon, L. K. Cannada and D. H. Jr., "Avoiding Complications in the Treatment of Hume- 
ral Fractures," The Journal of Bone and Joint Surgery (American), Vol. 90, No. 7, 2008, pp. 1580-1589.

[3] P. K. Beredjiklian, R. J. Naranja, R. B. Heppenstall, C. T. Brighton and J. L. Esterhai, "Results of Treatment of 111 Patients with Non-Union of Femoral Shaft Fractures," The University of Pennsylvania Orthopaedic Journal, Vol. 12, 1999, pp. 52-56.

[4] D. J. Hak, "Management of Aseptic Tibial Non-Union," Journal of the American Academy of Orthoapedic Surgeons, Vol. 19, No. 9, 2011, pp. 563-573.

[5] J. Gilles, S. Wallstabe, A. P. Schulz and U. Gerlach, "Is Non-Union of Tibial Shaft Fractures Due to Nonculturable Bacterial Pathologens? A Clinical Investigation Using PCR and Culture Techniques," Journal of Orthopaedic Surgery and Research, Vol. 7, No. 20, 2012, p. 20. www.josr-online.com/content/pdf/1749-799x-7-20.pdf http://dx.doi.org/10.1186/1749-799X-7-20

[6] C.-C. Wu, "Treatment of Long-Bone Fractures, Malunions and Non-Unions: Experience at Chang Gung Memorial Hospital, Taoyuan, Taiwan," Chang Gung Medical Journal, Vol. 29, No. 4, 2006, pp. 347-357.

[7] Z. U. Malik, K. M. N. T. Ahmed and A. K. S. T. S. Hussai, "Analysis of Causes and Treatment Modality in NonUnion of Long Bones Diaphyseal Fractures," Pakistani Armed Forces Medical Journal, Vol. 61, No. 3, 2011, pp. 433-437.

[8] A. M. Udosen, I. A. Ikpeme and N. E. Ngim, "Traditional Bonesetting in Africa: Counting the Cost," Proceedings of the 5th SICOT/SIROT Annual International Conference, September 2007, Marrakech, Morocco, p. 203.

[9] L. S. Phieffer and JA Goulet, "Delayed Unions of the Tibia, Instructional Course Lecture," Journal of Bone and Joint Surgery (American), Vol. 88, No. 1, 2006, pp. 205216.

[10] N. Wu, Y.-C. Lee, D. S. H. Murray, T. Wilcox and L. Boulanger, "Economic Burden of Illness among US Patients Experiencing Fracture Non-Union," Orthopaedics Research and Reviews, Vol. 2013, No. 5, 2013, pp. 21-33. http://dx.doi.org/10.2147/ORR.S41123

[11] C. R. Wheeless III, "Malunion of the Tibia," Wheeless Textbook of Orthopaedics, 2012. www.wheelessonline.com/ortho/malunion_of_the tibia

[12] J. A. Goulet and D. J. Hak, "Non-Unions and Malunions of the Tibia," In: M. W. Chapman, Ed., Chapman's Orthopaedic Surgery, Lippincott Williams \& Wilkins, Philadelphia, 2001, pp. 978-999.

[13] V. Perumal and C. S. Roberts, "Factors Contributing to Non-Union of Fractures," Current Orthopaedics, Vol. 21, No. 4, 2007, pp. 258-261. http://dx.doi.org/10.1016/j.cuor.2007.06.004
[14] J.-J. Yang, L.-C. Lin, K.-H. Chao, S.-Y. Chuang, C.-C. Wu, T.-T. Yeh and Y.-T. Lian, "Risk Factors for Non-Union in Patients with Intracapsular Femoral Neck Fractures Treated with Three Cannulated Screws Placed in Either a Triangle or an Inverted Triangle Configuration," The Journal of Bone \& Joint Surgery, Vol. 95, No. 1, 2013, pp. 6169. http://dx.doi.org/10.2106/JBJS.K.01081

[15] M. Lee, "Non-Unions of the Humerus," Journal of Hand Surgery, Vol. 18, No. 1, 2005, pp. 51-53.

[16] I. R. Murray, C. J. Foster and A. E. C. M. Robinson, "Risk Factors for Non-Union after Non-Operative Treatment of Displaced Midshaft Fractures of the Clavicle," The Journal of Bone \& Joint Surgery, Vol. 95, No. 13, 2003, pp. 1153-1158.

[17] L. A. Mills and A. H. R. W. Simpson, "The Relative Incidence of Fracture Non-Union in the Scottish Population (5.17 Million): A 5-Year Epidemiological Study," British Medical Journal Open, Vol. 3, No. 2, 2013, pp. 1-8. http://bmjopen.bmj.com/content/3/2/e002276.full.pdf + ht $\mathrm{ml}$

http://dx.doi.org/10.1136/bmjopen-2012-002276

[18] D. R. Marsh, S. Shah, J. Elliot and N. Kurdy, "The Illizayov Method in Non-Union, Malunion and Infection of Fractures," The Journal of Bone \& Joint Surgery, Vol. 79-B, No. 2, 1997, pp. 273-279. http://dx.doi.org/10.1302/0301-620X.79B2.6636

[19] G. V. Russell, M. L. Graves, M. T. Archdeacon, D. P. Barei, G. A. Brien Jr. and S. E. Porter, "The Clamshell Osteotomy: A New Technique to Correct Complex Diaphyseal Malunions," The Journal of Bone \& Joint Surgery (American), Vol. 91, No. 2, 2009, pp. 314-324. http://dx.doi.org/10.2106/JBJS.H.00158

[20] M. Tall, I. Quedraogo, A. N. Kasse, B. J. D. Tekpa, G. Bankoungou, S. Belem and M. F. Toe, "Femur Malunions Treated with Open Osteotomy and Intramedullary Nailing in Developing Countries," Orthopaedics \& Traumatology: Surgery \& Research, Vol. 98, No. 7, 2012, pp. 784-787.

[21] A. B. Omololu, S. O. Ogunlade and V. K. Gopaldasani, "The Practice of Traditional Bonesetting: Training Algorithm," Clinical Orthopaedics and Related Research, Vol. 466, No. 10, 2008, pp. 2392-2398. http://dx.doi.org/10.1007/s11999-008-0371-8

[22] A. A. Dada, W. Yinusa and S. O. Giwa, "Review of the Practice of Traditional Bonesetting in Nigeria," African Health Sciences, Vol. 11, No. 2, 2011, pp. 262-265.

[23] A. S. Gavaskar and R. Kumar, "Open Interlocking Nailing and Bonegratfing for Neglected Femoral Shaft Fractures," Journal of Orthopaedic Surgery, Vol. 18, No. 1, 2010, pp. 45-49. 